\title{
Resilience of planktonic bacterial community structure in response to short-term weather deterioration during the growing season in an alpine lake
}

\author{
Tianli Ma • Yiming Jiang • Ali H. A. Elbehery - Stephan Blank • \\ Rainer Kurmayer (D) $\cdot$ Li Deng
}

Received: 29 March 2019/Revised: 4 October 2019/Accepted: 29 October 2019/Published online: 15 November 2019

(C) The Author(s) 2019

\begin{abstract}
The disturbing effect of a short-term cooling period during summer on planktonic bacterial community structure of an alpine lake was investigated using $16 \mathrm{~S}$ rDNA pyrosequencing. Proteobacteria, Actinobacteria, and Bacteroidetes constituted the most abundant phyla. During the sampling period (from July to August 2010), a sudden cooling period with high precipitation occurred, as indicated by a decrease in conductivity, calcium, and dissolved organic carbon concentration resulting from increased runoff. The relative abundance of Actinobacteria,
\end{abstract}

Handling editor: Stefano Amalfitano

Electronic supplementary material The online version of this article (https://doi.org/10.1007/s10750-019-04118-8) contains supplementary material, which is available to authorized users.

T. Ma · Y. Jiang · A. H. A. Elbehery $\cdot$ L. Deng $(\square)$ Institute of Virology, Helmholtz Zentrum München, German Research Center for Environmental Health, Ingolstädter Landstrasse 1, 85764 Neuherberg, Germany e-mail: li.deng@helmholtz-muenchen.de

T. Ma · Y. Jiang · A. H. A. Elbehery $\cdot$ L. Deng Institute of Virology, Technical University of Munich, Trogerstrasse 30, 81675 Munich, Germany

S. Blank · R. Kurmayer $(\bowtie)$

Research Department for Limnology, Mondsee,

University of Innsbruck, Mondseestrasse 9,

5310 Mondsee, Austria

e-mail: rainer.kurmayer@uibk.ac.at
Betaproteobacteria, and Cyanobacteria decreased during this short-term cooling period. Instead, a rapid shift from Betaproteobacteria to Gammaproteobacteria occurred, which was mainly caused by an increase of Acinetobacter rhizosphaerae. Soon after the shortterm cooling period, warmer weather conditions got re-established and Betaproteobacteria recovered and became again dominant. Non-metric multi-dimensional scaling analysis and Venn diagrams revealed a planktonic bacterial community composition with high similarity at the beginning and the end of the growing season. Air temperature and precipitation were significantly correlated with the observed variation in operational taxonomic unit (OTU) relative abundance. It is concluded that, in response to the short-term cooling period, a distinct planktonic bacterial OTU community developed. It rapidly diminished, however, as summer conditions became reestablished, implying the recovery of the original bacterial community structure.

Keywords High mountain lake · Cooling period . Runoff $\cdot$ Resilience $\cdot$ Community turnover $\cdot$ Planktonic bacteria $\cdot$ Soil bacteria 


\section{Introduction}

Bacterial communities play crucial roles in decomposing organic matter and nutrient cycling in aquatic ecosystems (Salcher et al., 2010), and their activities are driven by multiple ecological factors such as temperature (Ren et al., 2013), pH (Stepanauskas et al., 2003), and nutrient concentration (Van Der Gucht et al., 2001; Yannarell \& Triplett, 2004). In lake ecosystems, local and climatic factors can affect the bacterial community by abiotic and biotic drivers (Battarbee et al., 2002; Castro et al., 2010). Although numerous studies have explored the effect of climatic changes on bacterial communities in lowland lakes (Allgaier \& Grossart, 2006; Comte et al., 2006; Bertilsson et al., 2007), fewer studies have considered remote lakes located in the alpine vegetation zone. Compared to lowland lakes, these lakes are considered relatively pristine due to less intensive anthropogenic activities taking place on or around them (Weckström et al., 2016). In addition, alpine lakes are considered sensitive to disturbance, e.g., through nutrient introduction (Heiri and Lotter, 2003), water temperature rises depending on the altitude range where the reduction in snow cover duration is most pronounced (Thompson et al., 2005), and predator effects by introduced fish (Magnea et al., 2013).

In recent years, studies have paid attention to the response of bacterial communities in alpine lakes to sudden changes in weather conditions. For example, the bacterial community structure in an arctic lake showed a rapid change over a short time period after snow melting or rain (Crump et al., 2003), mainly because transient bacteria were washed into the lake and some rare bacteria profited from terrestrial organic matter entering the lake via terrestrial runoff (Whalen \& Cornwell, 1985; O'Brien et al., 1997). In an experiment that simulated changes in soil characteristics induced by climate change, the availability of soil-derived phosphorus and carbon induced a change in the bacterial community structure within 3 days (Rofner et al., 2017). In addition to these indirect factors, temperature is one of the most important direct factors affecting the bacterial community structure (Lindström et al. 2005). Bacteria inhabiting in alpine lakes can adapt to local temperature by modulating membrane fluidity and gene expression (Yadav et al. 2016). Temperature can also indirectly mediate the release of nutrients from sediment and trophic transfer and further affect bacterial growth and diversity (Rasconi et al., 2017). The resilience of bacterial communities to disturbance in general has been studied widely (e.g., Shade et al., 2012), and it has been generally argued that microbial composition is resilient and quickly return to its pre-disturbance state because of fast growth rate and physiological flexibility (e.g., Allison \& Martiny, 2008). In lake ecosystems, studies have shown that the planktonic bacterial community (as well as phytoplankton or zooplankton) indeed return to their pre-disturbance state after experiencing pesticide input (Downing et al., 2008), disturbance of the water column stability caused by typhoon (Jones et al. 2008), or human intervention (Shade et al., 2011). Fewer studies have been performed in remote unproductive and relatively cold alpine lakes where the role of climatic disturbance might be more influential compared to warmer and more productive lowland regions. In a recent study, the average water temperature after ice break in spring until the sampling date has been observed as a limiting factor during the earlier growing season in alpine lakes (Jiang et al., 2019).

This study aimed investigate the changes in the bacterial community structure during the summer growing season occurring in a remote alpine lake, Unterer Giglachsee in the Niedere Tauern at $1922 \mathrm{~m}$ asl, in response to a local cooling period disturbance linked to rain and snowfall. For this purpose, we (i) monitored the local weather and environmental conditions, (ii) described the bacterial community composition turnover at the phylum, class, and genus levels, (iii) analyzed the effect size of meteorological conditions in comparison to chemicophysical parameters, and (iv) compared the bacterial community composition at the beginning and the end of the observation period to describe the resilience after the disturbance by the short-term cooling period.

\section{Materials and methods}

Site description and sampling

Unterer Giglachsee $\left(47.28^{\circ} \mathrm{N}, 13.65^{\circ} \mathrm{E}\right)$ is an oligotrophic alpine lake, which is located in a catchment area dominated by carbonaceous bedrock (limestone and dolomite) at the tree and timberline. The altitude, length, width, depth, and area are $1922 \mathrm{~m}$ asl, 
$1 \mathrm{~km}, 40$ to $280 \mathrm{~m}, 18 \mathrm{~m}$, and 16.5 ha, respectively. Further detailed information is given by Weckström et al. (2016). Meteorological parameters for this area (including air temperature, average wind speed, precipitation, sunshine hours, and snow layer) were obtained from Zentralanstalt für Meteorologie und Geodynamik, who run three weather monitoring stations located more closely in the alpine region: Obertauern Station (1772 m), Rudolfshütte Station (2317 m), and Schmittenhöhe Station (1956 m). Water thermistors (MINILOG, Vemco Ltd.) were installed at $2.5 \mathrm{~m}$ depth in the deepest parts of the lake and used to monitor water temperature every $4 \mathrm{~h}$. Depth-integrated water samples (1.5-2 1) were collected at the deepest part of the lake on July 19, 21, 27, and 31 and August 01, 04, 09, and 18 of year 2010. The water samples were first pre-filtered in the field through glass fiber filters using a hand vacuum pump (GF/C) to remove most of the eukaryotic algae and particle-associated bacteria. Then, the filtrate was filtered through nitrocellulose (NC) membranes (pore diameter $0.2 \mu \mathrm{m}$ ). $\mathrm{NC}$ membranes were transferred into Eppendorf tubes and were stored at $-20^{\circ} \mathrm{C}$ until DNA extraction.

DNA extraction, 16S rDNA amplification, and sequencing

$\mathrm{NC}$ membranes were loaded into a bead beater tube to physically break the cells, and DNA was subsequently isolated and purified using a NucleoSpin ${ }^{\circledR}$ Soil DNA extraction kit (Macherey-Nagel, Germany) and eluted in $40 \mu \mathrm{l}$ elution buffer. The quality and quantity of extracted DNA were estimated using a NanoDrop ${ }^{\circledR}$ ND-1000 spectrophotometer (Thermo Fisher Scientific). The extracted bacterial genomic DNA (100 ng) was amplified in a 50- $\mu \mathrm{l}$ reaction mix containing $10 \mu \mathrm{l}$ of $5 \times$ buffer HF, $1 \mu \mathrm{l}$ of $10 \mathrm{mM}$ of each deoxynucleotide triphosphate, 1 unit of a proofreading polymerase (Phusion Hot Start High-Fidelity DNA Polymerase; Thermo Fisher Scientific), and $2.5 \mu \mathrm{l}$ of forward and reverse primers $\left(10 \mathrm{pmol} \mu \mathrm{l}^{-1}\right)$ binding to conserved regions (V3 and V6) within the 16S rDNA. The forward primer (338F: 5'-CGTATCGCCTCCCT CGCGCCA TCAG ACGAGTGCGT ACTCCTA CGGGAGGCAGCA ${ }^{\prime}-3^{\prime}$ ) and the reverse primer (1046R: 5'-CTATGCGCCTTGCCAGCCCGC TCAG ACGAGTGCGT CGACAGCCATGCANCACCT-3') included the sequences representing the adaptor, key, and barcode sequence (underlined and separated by a space), whereas the specific sequence binding to bacterial rDNA is indicated at the $3^{\prime}$ end (Huse et al., 2008). Polymerase chain reaction (PCR) products (709 bp) were obtained under the following cycling conditions: annealing temperature at $67.8^{\circ} \mathrm{C}$, elongation for $30 \mathrm{~s}$, and 20 cycles. After running the gel, PCR products were cut out from agarose gel and purified using the gel purification kit (Qiagen, Hilden, Germany). Four independent PCR amplicons were pooled. Purified amplicons were sequenced using a GS-FLX platform with 454 titanium chemistry. Four amplicons were sequenced in four regions separated by fourregion gaskets, loading approximately $3,100,000$ amplicon-coated beads per run and recovering a total of 800,000 sequence tags.

\section{S rDNA sequence processing}

The sequences were processed using QIIME 19.0 (Caporaso et al., 2010). The multiplex reads were assigned to the original samples based on their barcode sequences. The raw reads were filtered by quality (Phred quality score $>2$ ) and the sequences were clustered into operational taxonomic units (OTUs) at 97\% sequence similarity. The UCLUST (Edgar, 2010) consensus taxonomy classifier was used to identify bacterial phylotypes from assigned OTUs. Representative sequences from each phylotype were aligned using PYNAST (Caporaso et al., 2009) and the sequence that was found to be most abundant in each OTU cluster was selected as the representative sequence. The Greengenes database (DeSantis et al., 2006) was used to identify the taxonomy of each phylotype. The raw sequencing data have been deposited in the National Center for Biotechnology Information (NCBI) Raw Sequence Read Archive under the following accession numbers: SAMN0990 6023, SAMN09906024, SAMN09906025, SAMN09 906026, SAMN09906027, SAMN09906028, SAMN 10743546, and SAMN10743550.

Statistical data analysis

Non-metric multi-dimensional scaling (NMDS) based on "Bray-Curtis" similarities was used to compare the bacterial community composition at the OTU level between samples (including all OTUs $>0.1 \%$ in total 
reads). Analysis was performed using R (version 3.2, package vegan). Analysis of similarities (ANOSIM) was used to test whether there was a significant difference between groups of samples as identified by NMDS. Venn diagram analysis was performed at http://www.interactivenn.net/ and used to illustrate the OTUs shared between samples. For clarity, we only chose the most abundant OTUs ( $>1 \%$ in total reads) in each sample. All other graphs were generated with OriginLab 8.

To study the relationship between bacterial community composition at the OTU level and meteorological variables, detrended correspondence analysis was applied to test whether a unimodal or a linear relationship between OTUs and variables was appropriate. The length of gradient varied from 3 to 4 , implying that both unimodal and linear models could be used. The linear redundancy analysis (RDA) method was chosen (Lepš \& Šmilauer, 2003), including the time dependence of consecutive samples as a covariate. As deduced from variance inflation factors, the variables air temperature (at noon) and sunshine hours showed high correlation. Thus, the latter were excluded from further analysis and the meteorological variables (air temperature, precipitation, and average wind speed) were tested using the forward selection procedure $(P<0.05)$. A Monte Carlo permutation test (499 randomized data sets) was used to test whether the influence of axis 1 was statistically significant at $P<0.05$. Ordination analysis was performed using CANOCO software for Windows (version 4.5).

\section{Results}

Weather and environmental conditions during the study period

In general, relatively warm (average $\pm \mathrm{SE}$ air temperature at noon, $15.1{ }^{\circ} \mathrm{C} \pm 0.12^{\circ} \mathrm{C}$ ) and good weather during July 2010 was followed by a distinct cooling period at the end of July, as indicated by a decrease in air and water temperature (Fig. S1). The average \pm SE air temperature during the cooling period was $6.7^{\circ} \mathrm{C} \pm 0.31^{\circ} \mathrm{C}$. On July 27 , conductivity, calcium, and dissolved organic carbon (DOC) values all declined, indicating a significant runoff of rain and melting snow (Fig. 1). As this change was observed for a short time only, it was concluded that runoff influence declined again in the second part of the study period, i.e., during August 2010. Nevertheless, water temperature remained relatively low compared to the summer period before the cooling period.

Sequencing output

A total of 104,612 raw sequences were obtained. After the removal of linkers, barcodes, and primers, as well as low-quality or ambiguous reads, a total of 89,508 high-quality reads were identified. For individual sampling dates, read numbers ranged from 2,041 to 20,611 (Table 1). In total, 2,484 OTUs were selected by applying the $97 \%$ sequence similarity threshold. Low abundance reads $(<0.1 \%$ in total reads) were removed for further analysis, resulting in 436 OTUs. The value of "Goods_coverage" indicated that, for all samples, the sequencing depth was sufficient to represent the actual microbial diversity.

Bacterial community composition at the phylum and class levels

Proteobacteria, Actinobacteria, Bacteroidetes, Cyanobacteria, Chloroflexi, Firmicutes, Thermi (Deinococcus-Thermus), and Verrucomicrobia constituted the most abundant phyla in the bacterial community composition (Fig. 2a). On average, Proteobacteria, Actinobacteria, and Bacteroidetes accounted for $>90 \%$ of all OTUs, with Proteobacteria constituting the most abundant phylum. Only on August 09, which was after the cooling period, the relative abundance of Actinobacteria reached 43.1\% and exceeded that of Proteobacteria. Within the Proteobacteria, Alphaproteobacteria, Betaproteobacteria, Deltaproteobacteria, and Gammaproteobacteria constituted the four major classes (Fig. 2b). In general, the relative abundance of Deltaproteobacteria was the lowest $(<1 \%)$. Alphaproteobacteria ranged in relative abundance from $5.0 \%$ to $16.8 \%$. However, during the cooling period (on July 27 and 31), the relative abundance of Gammaproteobacteria reached maxima of $55.9 \%$ and $46.8 \%$, respectively. Furthermore, during the cooling period, the relative abundance of Betaproteobacteria was lower on July 27 (14.2\%) and July $31(14.6 \%)$ and lowest on August 09 (13.1\%) compared to other sampling dates (30.2-47.8\%). On average, the relative abundance of Actinobacteria was much lower during the cooling period $(10.3 \%, 13.0 \%$, 
Fig. 1 a Water chemicophysical parameters and $\mathbf{b}$ air temperature and water temperature in the alpine lake Unterer Giglachsee during July and August 2010. The shortterm cooling period is indicated by the shaded area

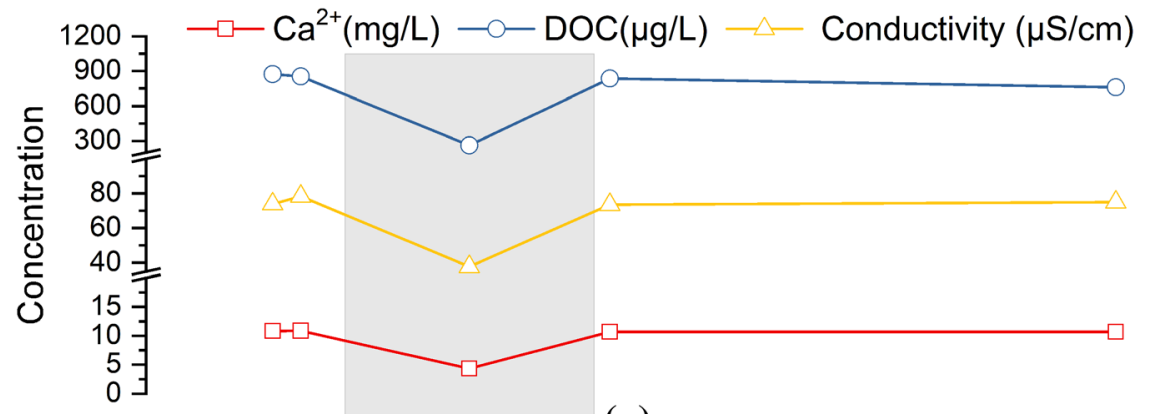

(a)

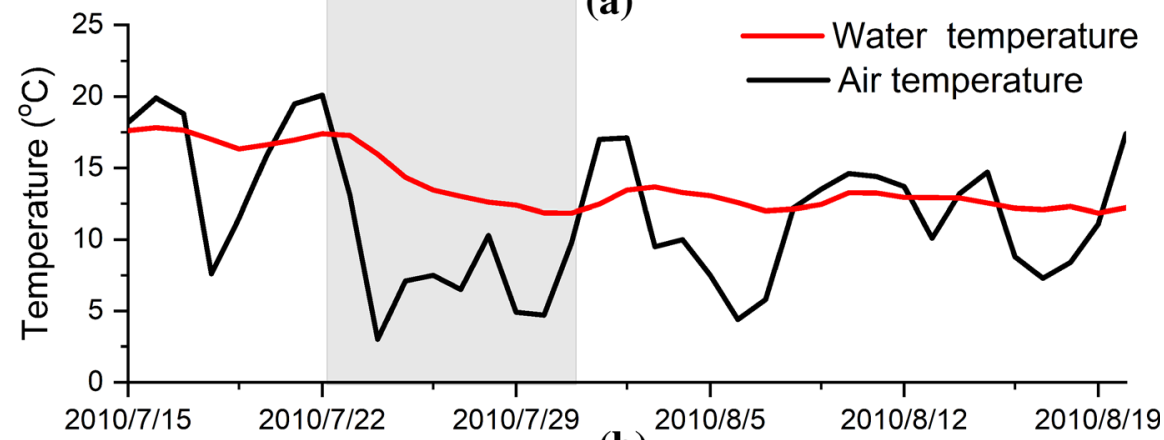

(b)

Table 1 Sequencing output for samples from alpine lake Unterer Giglachsee analyzed in the course of a cooling period in July/ August 2010

\begin{tabular}{lcllllll}
\hline Sampling (date) & Total reads & Total OTUs & Goods_coverage & Chao1 & Fisher & Shannon & Simpson \\
\hline July 19 & 5,647 & 375 & 0.967 & 747 & 99.81 & 5.38 & 0.92 \\
July 21 & 10,308 & 390 & 0.984 & 670.78 & 84.88 & 5.69 & 0.96 \\
July 27 & 11,759 & 328 & 0.985 & 766.9 & 66.49 & 3.49 & 0.7 \\
July 31a & 20,611 & 419 & 0.991 & $553.04^{\mathrm{a}}$ & $50.56^{\mathrm{a}}$ & $4.09^{\mathrm{a}}$ & $0.82^{\mathrm{a}}$ \\
July 31b & 7,227 & 245 & 0.983 & & & & \\
August 01 & 2,260 & 280 & 0.942 & 504.4 & 88.99 & 6.22 & 0.97 \\
August 04 & 19,027 & 489 & 0.988 & 904.64 & 96.99 & 5.31 & 0.94 \\
August 09 & 10,628 & 366 & 0.985 & 630.39 & 77.07 & 5.74 & 0.96 \\
August 18 & 2,041 & 366 & 0.897 & 817.21 & 154.93 & 6.31 & 0.95 \\
\hline
\end{tabular}

${ }^{\mathrm{a}} \mathrm{July} 31 \mathrm{a}$ and July31b were used as technical replicates and were combined subsequently

and $6.4 \%$ on July 27, July 31, and August 01, respectively) compared to warmer weather conditions before and after. Similarly, the relative abundance of Bacteroidetes decreased on July 27 and 31 (9.2\% and $6.3 \%$, respectively) compared to warmer weather conditions before and after. The relative abundance of Cyanobacteria ranged from $1.6 \%$ to $5.4 \%$ and showed a similar trend of decline during the cooling period, with results for July 27 and 31 of $1.6 \%$ and $2.2 \%$, respectively. On average, the other phyla (Nitrospirae, Gemmatimonadetes, Chlorobi, and Acidobacteria) contributed $<1 \%$ of all OTUs. Thus, whereas the Gammaproteobacteria class seemed to increase during the short-term cooling period, other phyla and classes regained abundance once warmer weather conditions were re-established.

Short-term changes in the bacterial community composition at the genus level

In all samples, the genera that were taxonomically classified belonged to the phyla Proteobacteria, Actinobacteria, Firmicutes, Cyanobacteria, Bacteroidetes, and Thermi (Fig. 3). The relative abundance of the 


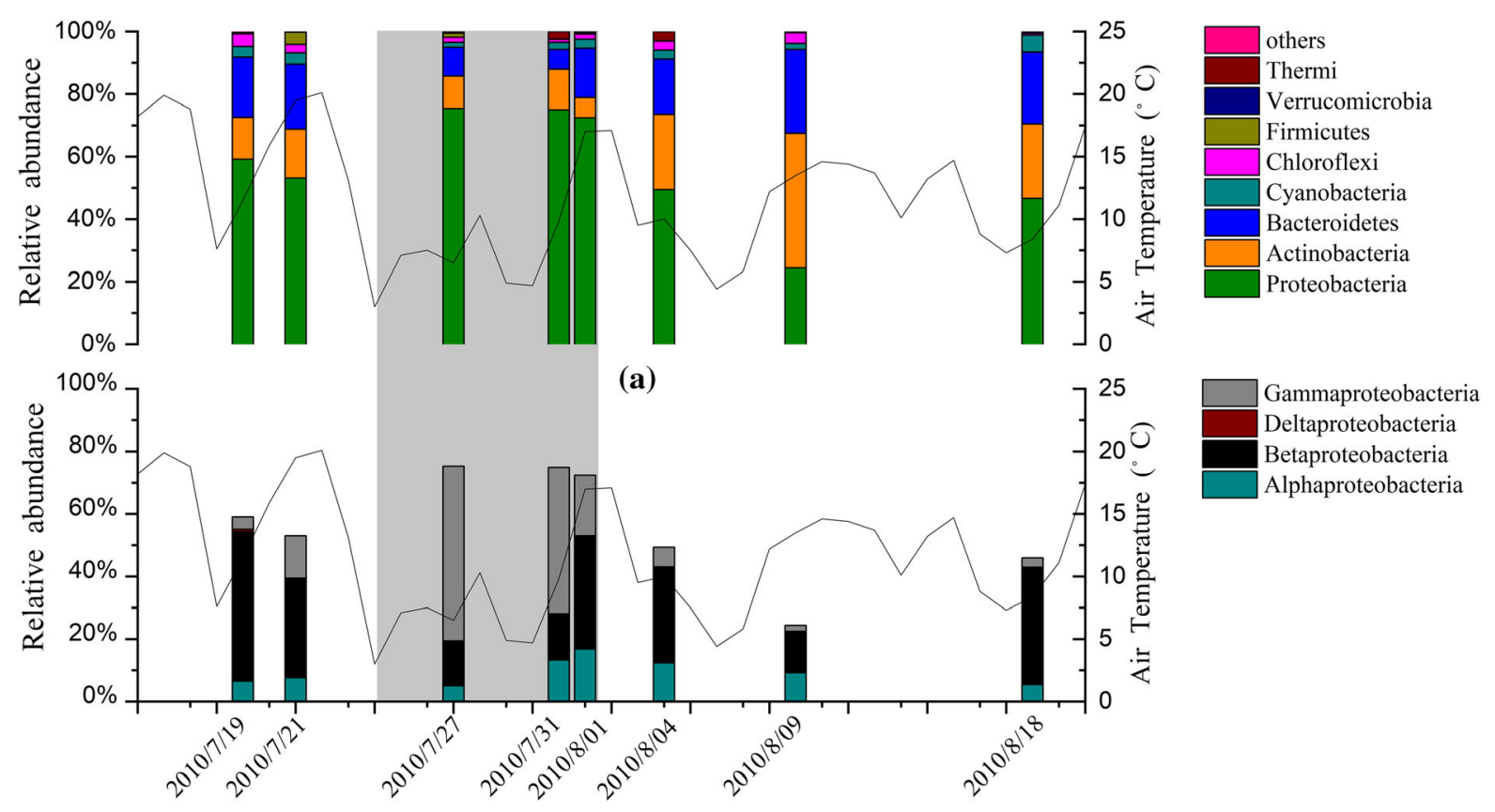

(b)

Fig. 2 Relative abundance of $\mathbf{a}$ bacterial phyla and $\mathbf{b}$ classes of Proteobacteria in the alpine lake Unterer Giglachsee during July and August 2010. The air temperature at noon (12:00 midday) is

assigned genera was highest on July 27 and 31, i.e., $64.5 \%$ and $62.8 \%$ and $<50 \%$ on all other sampling dates. Eight genera assigned to Proteobacteria were identified, with Acinetobacter, Limnohabitans, Sphingomonas, and Polynucleobacter found to be the most abundant (Fig. 4a). Several genera showed a significant increase in relative abundance in coincidence with the short-term cooling period. During the study period, Acinetobacter (17 OTUs) increased in relative abundance and occurred in highest number during the short-term cooling period, i.e., on July 27 and 31 (54.7\% and $45.5 \%$, respectively). Sphingomonas was not detected on July 19 and August 18, whereas it occurred at high relative abundance on July 31 , August 01 , and August 04 (3.2\%, 7.4\%, and 3.0\%, respectively). However, the abundance of Limnohabitans (13 OTUs) declined to a minimum during the cooling period $(0.3 \%$ and $0.4 \%$ on July 27 and 31 , respectively), whereas its highest relative abundance was observed on July $21(10.2 \%)$ followed by August 01 and 09 (7.7\% and $4.0 \%$, respectively). Similarly, the relative abundance of Polynucleobacter was higher at the beginning (July 19; 9.1\%) and at the end (August indicated by the straight gray line. The deterioration in weather conditions is indicated by the shaded area

$18 ; 6.8 \%$ ) of the study period but declined during the short-term cooling period.

Within Actinobacteria, three genera with low abundance were identified, including Propionibacterium (1 OTU), Rhodococcus (2 OTUs), and Mycobacterium (3 OTUs; Fig. 4b). Within Cyanobacteria, the relative abundance of Synechococcus (7 OTUs) ranged from $0.1 \%$ (August 09) to $5.1 \%$ (August 18) and decreased during the short-term cooling period on July 27 (1.5\%) and July 31 (2.1\%; Fig. 4c). Within Bacteroidetes, Flavobacterium (7 OTUs), Fluviicola (15 OTUs), and Sediminibacterium (14 OTUs) were identified (Fig. 4d). The relative abundance of Flavobacterium ranged from $0.04 \%$ on July 31 to $1.3 \%$ on July 19 . Fluviicola decreased in relative abundance during the cooling period $(0.4 \%$ and $0.6 \%$ on July 27 and 31 , respectively) and increased at the end of the study period $(3.0 \%, 7.3 \%$, and $3.0 \%$ on August 04, 09, and 18, respectively). Similarly, the relative abundance of Sediminibacterium decreased on July 27 and $31(0.7 \%$ and $0.5 \%$, respectively), whereas it occurred with higher relative abundance at the beginning and end of the observation period, i.e., on August 04 and 09 (1.3\% and 7.3\%, 


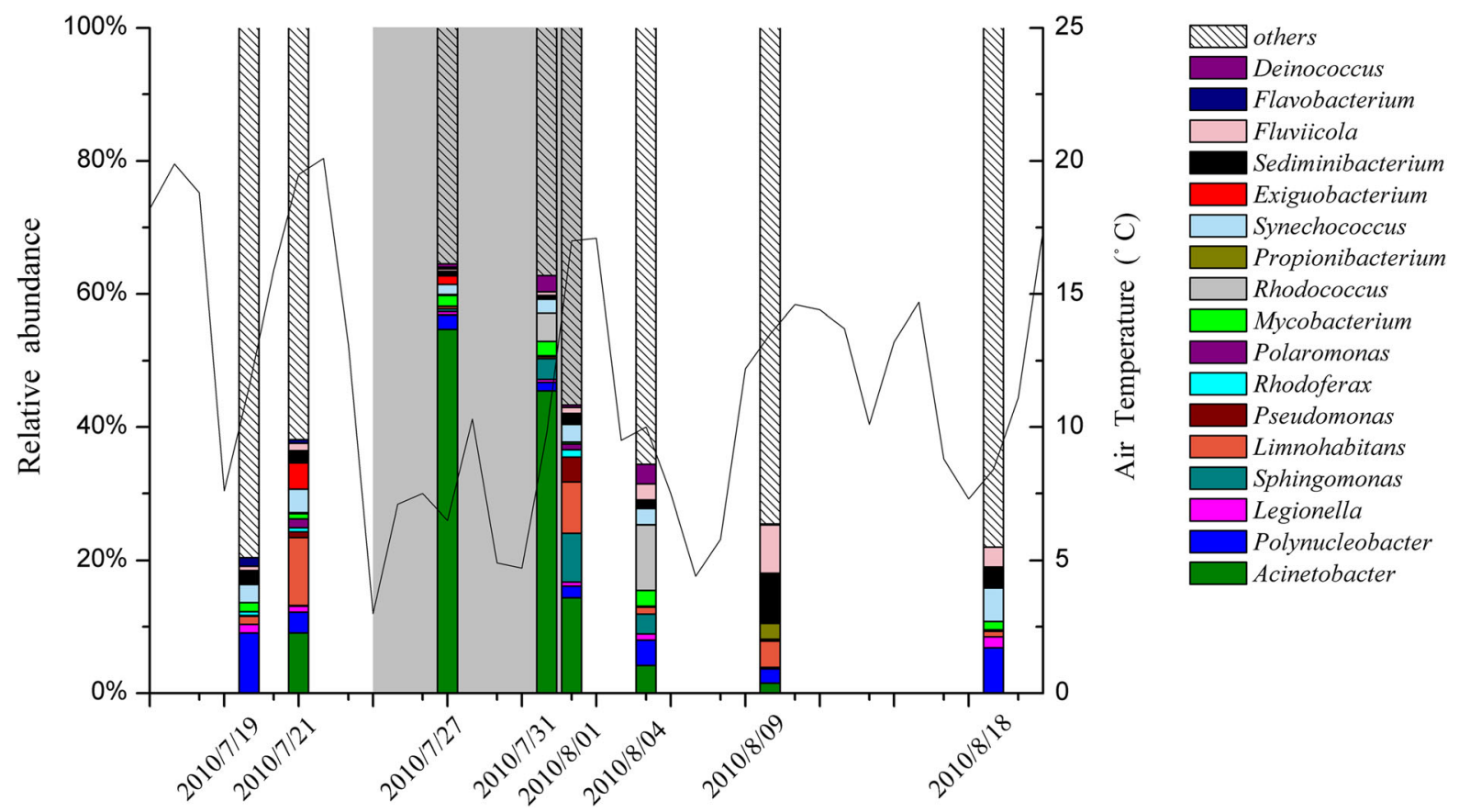

Fig. 3 Relative abundance of bacterial genera in the alpine lake Unterer Giglachsee during July and August 2010. The air temperature at noon (12:00 midday) is indicated by the straight gray line. The deterioration in weather conditions is indicated by the shaded area

respectively). In summary, these results showed that a distinct change in the bacterial community composition coincided with the short-term cooling period.

Similarity of the bacterial community structure at the OTU level

Accordingly, with changes in community composition, a lower richness and diversity were observed on July 27 and 31, coinciding with the short-term weather change (Table 1). Three groups of samples were identified using NMDS analysis (including OTUs $>0.1 \%$ in total reads). Group 1 included OTUs on July 27 and 31, which was during the short-term weather deterioration. Two technical replicates of sequencing (July 31a and $31 \mathrm{~b}$ ) were found to be most similar, indicating that there was good reproducibility. Group 2 included OTUs in the beginning and the end of the study period, i.e., July 19, August 04, and August 18. The OTUs obtained on July 21, August 01, and August 09 formed Group 3 (Fig. S2). ANOSIM revealed marginally significant differences between two groups (Groups 1 and 2, Groups 2 and 3, and Groups 1 and 3; $R=1$, $P=0.1$ ). Indeed, the differences among the three groups were significantly greater than the differences within groups $(R=0.89, P<0.01)$. The bacterial community structure was compared using Bray-Curtis similarity indices among three dates representing the beginning of the study period (July 19), the cooling period (July 31), and the end of the study period (August 18), respectively. Notably, bacterial community structure on July 19 and August 18 (similarity index $=0.79$ ) was found more similar compared to July 19 and 31 (similarity index $=0.67$ ), implying that the bacterial community structure recovered under nice weather conditions.

In addition to NMDS analysis, the most abundant OTUs ( $>1 \%$ in total reads; Table S1) were analyzed using Venn diagrams to illustrate which OTUs were shared between samples (15-22 OTUs per sample). Venn diagrams showed that three separate groups were formed (Fig. S3): Group 1 comprised OTUs from July 21, August 01, and August 09 only, sharing 5 OTUs belonging to the orders Acidimicrobiales, Cytophagales, Burkholderiales, and Pseudomonadales. In contrast, Group 2 comprised OTUs from the cooling period (July 27 and 31) only, sharing 9 OTUs belonging to the orders Pseudomonadales, Burkholderiales, Sphingomonadales, Rhizobiales, Synechococcales, Cytophagales, and the families 
Proteobacteria

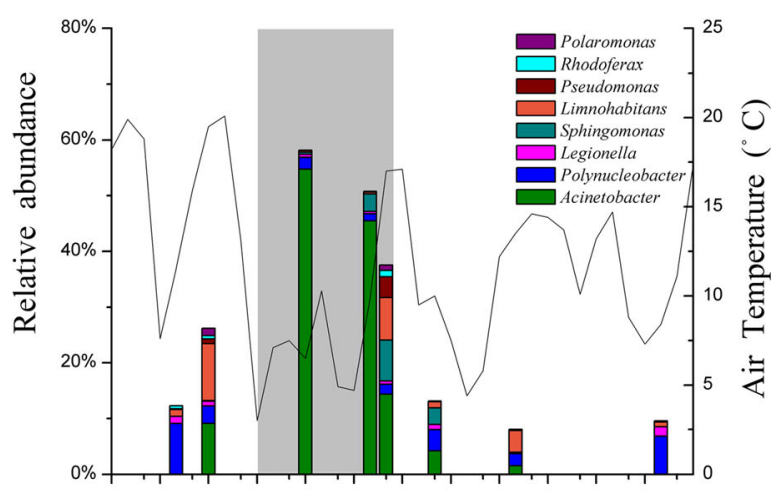

(a)

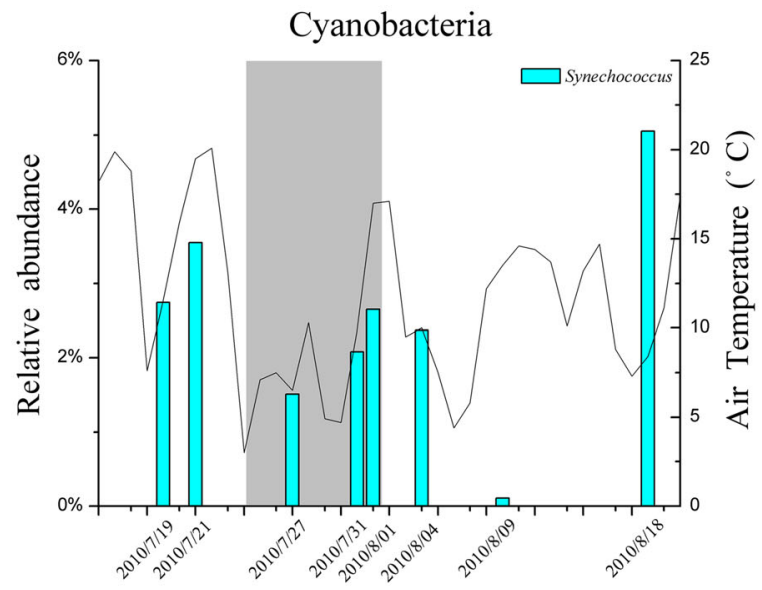

(c)

Fig. 4 Relative abundance of abundant bacterial genera from different phyla a Proteobacteria, b Actinobacteria, c Cyanobacteria, and $\mathbf{d}$ Bacteroidetes in the alpine lake Unterer Giglachsee

Mycobacteriaceae, C111. Group 3 comprised OTUs occurring at the beginning and the end of the study period (July 19, August 04, and August 18), sharing 8 OTUs belonging to the orders Burkholderiales, Sphingomonadales, Cytophagales, and the families Mycobacteriaceae, C111. In summary, the OTUs shared between the sampling dates at the beginning and the end of the study period supported the conclusion that the bacterial community became reestablished after the short-term cooling period.

Relationship between the bacterial community composition and meteorological variables

RDA was used to explore the relationship between the bacterial community composition at the OTU level $(>1 \%$ in total reads) and meteorological variables.
Actinobacteria

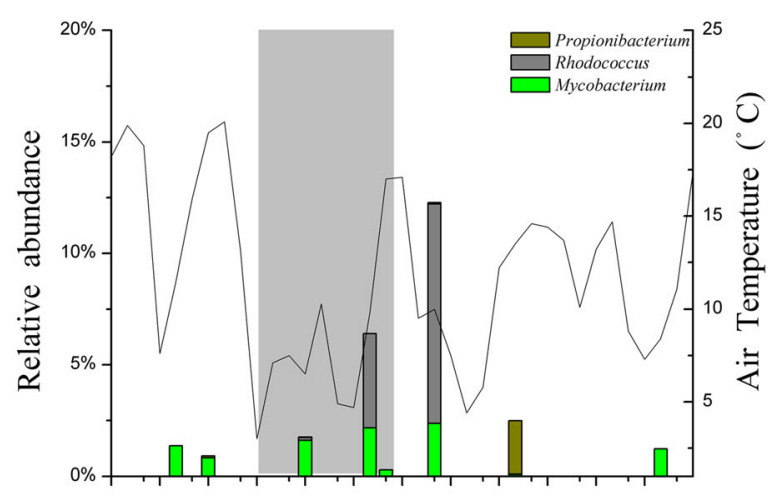

(b)

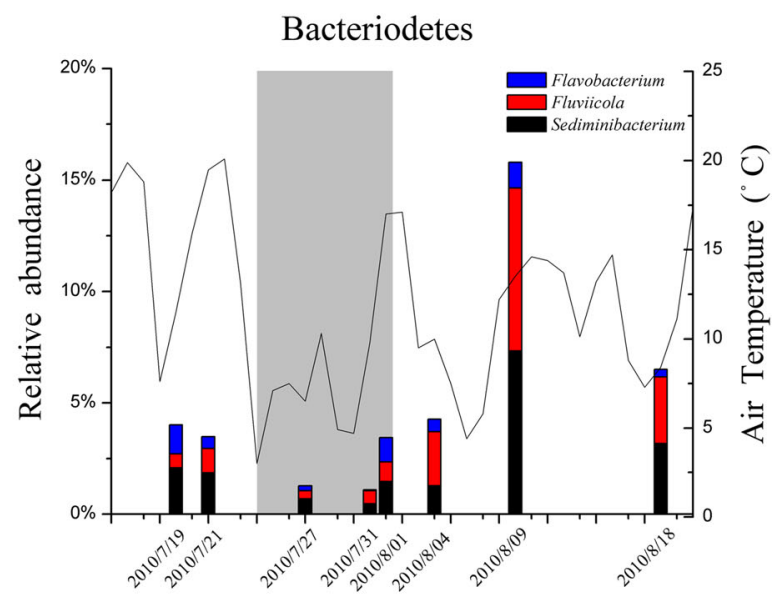

(d)

during July and August 2010. The air temperature at noon (12:00 midday) is indicated by the straight gray line. The deterioration in weather conditions is indicated by the shaded area

Using the most abundant taxa (75 OTUs), two variables were identified by forward selection (using time dependence as a covariate). Air temperature and precipitation significantly explained the observed variation in the bacterial community composition at OTU level $(P=0.012)$. The two factors were found to be relatively unrelated to each other as they were plotted roughly orthogonally (Fig. 5). The canonical axis 1 explained $33 \%$ of the total variability in the OTU data, implying a distinct gradient of air temperature, whereas the canonical axis 2 explained $15 \%$ of the variability related to precipitation. Variance partitioning revealed that the explanatory effect of air temperature only was still significant $(P=0.026)$, although the total variability explained decreased from 53 to $29 \%$. The influence of precipitation was found 


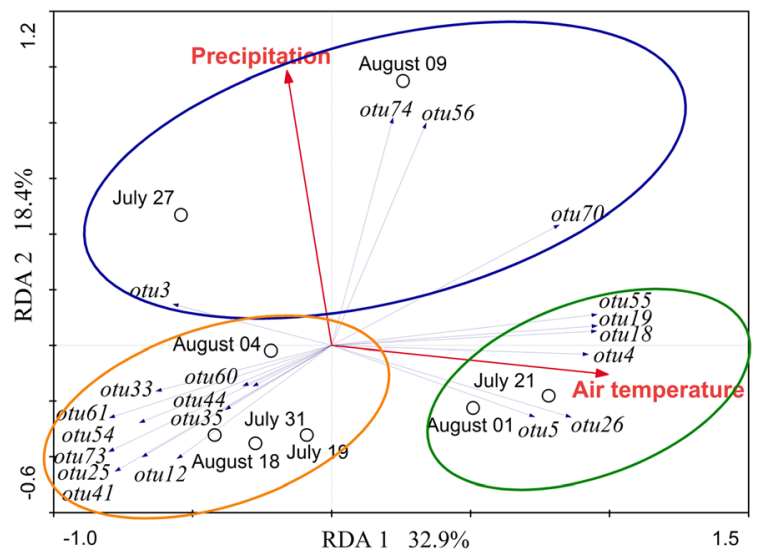

Fig. 5 Redundancy analysis (RDA) of bacterial OTUs (>1\% in total reads) and environmental variables. The two canonical axes explained $47 \%$ of the microbial community differentiation, $P$ value $=0.012$. For clarity, only the twenty most abundant OTUs are shown. Taxa represented by OTUs 1-75 are listed in Table S1

marginally significant $(P=0.07)$, and the total variability explained declined to $34 \%$. It is concluded that both variables represented non-redundant gradients determining bacterial OTU composition. Three groups of OTUs were identified. One group was positively correlated with precipitation, including the genera Acinetobacter and Sediminibacterium and unknown genera from families $\mathrm{C} 111$ and Cerasicoccaceae. The other two groups were correlated negatively or positively with air temperature. One group was related positively to air temperature, including unknown genera of families Comamonadaceae and Cytophagaceae and the genera Acinetobacter and Limnohabitans. The other group was related negatively to air temperature, including unknown genera from the orders Sphingomonadales, Roseiflexales, the families C111, Cytophagaceae, Comamonadaceae, and Methylobacteriaceae and the genera Rhodococcus, Mycobacterium, Synechococcus, and Polynucleobacter. It is concluded that, in response to the short-term cooling period, a rather distinct aquatic bacterial OTU community developed but rapidly diminished when summer conditions got re-established.

Among the most abundant bacteria, Acinetobacter rhizosphaerae (OTU No3) was positively correlated with precipitation and negatively correlated with air temperature. Compared to other samples, OTU No3 had a pronounced increase in relative abundance (July 27 at $53.05 \%$ and July 31 at $40.47 \%$ ) during the cooling period (Table S1). The sequence of OTU No3 was blasted against the NCBI database, and the metadata of the hits indicated that these bacteria originated from soil (Chanika et al., 2011; Kasana 2017) and the plant root system (Jossi 2008; Marasco et al., 2013).

\section{Discussion}

Influence of weather deterioration on lake planktonic bacterial community

During the cooling period, there was a notable drop in conductivity and $\mathrm{Ca}^{2+}$ concentration, which indicated a terrestrial runoff influence. The $\mathrm{Ca}^{2+}$ concentration was reduced by almost one-third within a few days, implying that slow-growing species were washed out due to a lacking competitiveness (Hibbing et al., 2010). In addition, terrestrial runoff can increase organic matter transport and input to the lake (Tranvik \& Jansson, 2002; Hongve et al., 2004; Worrall et al., 2018) leading to resource diversification, i.e., organic matter is carried into lakes from terrestrial plants and soils through catchment runoff (Crump et al., 2003). In this study, however, DOC concentration declined during weather deterioration, implying that increased precipitation resulted in lake water dilution rather than enrichment with organic matter from terrestrial runoff. In summary, the cooling period led to a detectable disturbance of the alpine planktonic habitat, which became reversed as soon as the source of disturbance disappeared. It has been argued that every ecosystem reacts to environmental changes in a relatively predictable manner depending on its biological capacity. In general, extreme environments such as arctic/ alpine ecosystems are known to be more sensitive to various kinds of disturbance because of various growth-limiting factors. Nevertheless, it has been suggested that disturbance and climate change might interact, e.g., early successional ecosystems may be more sensitive to climate change influence compared to later successional states, thus resulting in state shifts only when disturbed (Kröel-Dulay et al., 2015). Aquatic ecosystems have long been studied for regime and state shifts induced by non-linear ecosystem behavior in relatively short periods (Scheffer and Carpenter 2003). Such regime shifts would have significant consequences on the ecosystem level, 
e.g., high algal biomass production during summer and oxygen consumption during the ice cover period resulting in a cascade of changes in the whole ecosystem. Modeling experiments have revealed that such regime shifts can be foreseen already through long-term monitoring by statistical anomalies, i.e., through the increased variance in residues from dependent variables in linear regression models (Seekell et al., 2011). In other words, weather-induced disturbances might actually increase the variance in dependent variables to a potential extent, which possibly increases the likelihood of state shifts. In a related study, runoff events induced by precipitation were compared in five alpine lakes (Jiang et al., 2019). Notably, the evidence that richness or diversity may be influenced by runoff through rainfall or snow melting during two summer periods in 2010 and 2011 was found relatively low, implying that the pronounced cooling period observed in this study was rather the exception than the rule. In summary, a potential interaction between weather-induced disturbances and climate change effects should be considered, in particular for alpine systems known to be more sensitive to temperature rise effects than lowland aquatic ecosystems.

Changes in the bacterial community composition at the phylum level

In general, five phyla have been frequently reported in lakes, including Proteobacteria, Actinobacteria, Bacteroidetes, Cyanobacteria, and Verrucomicrobia (Newton et al., 2011). In this study, the two main classes of Proteobacteria, namely Betaproteobacteria and Gammaproteobacteria alternated in relative abundance with dominance of Gammaproteobacteria during the cooling phase. Only a few studies showed that Gammaproteobacteria occurred in high abundance in mountain lakes (Power et al., 2005), although this class usually was found to be dominant under deepwater conditions only (Bel'kova et al., 1996). Some authors also concluded that this group may be transiently washed into lakes with surface runoff (Lindström \& Leskinen, 2002). In our study, the high relative abundance of Gammaproteobacteria during the cooling period was possibly caused by the rapid growth of A. rhizosphaerae. In general, Betaproteobacteria are typically found to be dominant in the euphotic zone of a lake (Bel'kova et al., 1996) and are known to respond quickly to changes in nutrient availability (Hornák et al., 2006; Posch et al., 2007; Nelson, 2009). When nutrient concentrations are high, Betaproteobacteria tend to be fast growing (Newton et al., 2011). In our study, after the cooling period, Betaproteobacteria rapidly regained dominance probably because of their fast growth rate under more favorable DOC concentrations. In addition, the relative abundance of Cyanobacteria during the entire study period was relatively low. This low relative abundance might be a result of the overall oligotrophic conditions as higher abundance of Cyanobacteria typically occurs in more eutrophic freshwater (Eiler $\&$ Bertilsson, 2004). In addition, Cyanobacteria are sometimes favored by increased temperature (Paerl \& Huisman, 2008). Similar to Betaproteobacteria, the growth of Bacteroidetes is also related to organic matter resulting from a phytoplankton bloom (Newton et al., 2011) and frequently occurs during periods with high external DOC loading and algae-derived DOC production (Eiler \& Bertilsson, 2004; Kolmonen et al., 2004). Accordingly, in our study, the increased relative abundance of Bacteroidetes coincided with the period of higher DOC and higher Cyanobacteria relative abundance. Actinobacteria are ubiquitous in freshwater lakes (Haukka et al., 2006; Humbert et al., 2009) but favor less eutrophic conditions (Haukka et al., 2006). Previous studies confirmed that their abundance decreased with decreasing oxygen concentration (Taipale et al., 2009). As Actinobacteria are typically small and slow-growing, they might have been disfavored by the cooling period in our study. The relative abundance of Verrucomicrobia was generally low in all samples, which can be explained by their overall dependence on more eutrophic conditions (Newton et al., 2011). Other phyla occurred in lowest relative abundance, which might be caused by specific local conditions, including lake type, local weather conditions, nutrient availability, physical and chemical properties, catchment characteristics, and others (Crump et al., 2003; Corno, 2006; Bertilsson et al., 2007; Corno et al., 2009).

Short-term succession of the bacterial community related to the cooling period

It was obvious that Acinetobacter, affiliated to Proteobacteria, had a successional development along with temperature decrease. Previous studies have 
reported that many members of Acinetobacter, isolated from oligotrophic conditions, also had a higher tolerance to low temperatures and can grow well in cold environments (Huang et al., 2013; Yao et al., 2013). In our study, A. rhizosphaerae was frequently identified during the cooling period and probably originated from rhizospheric soil (Kasana, 2017). The known higher growth rate of $A$. rhizosphaerae under low-temperature conditions $\left(3.0^{\circ} \mathrm{C}-10.3^{\circ} \mathrm{C}\right)$ might have supported the net bacterial growth even under higher flow-through conditions as indicated by the dilution of $\mathrm{Ca}^{2+}$ and DOC concentrations. However, another genus, Limnohabitans, which is also affiliated to Proteobacteria, is known to have a high growth and substrate uptake rate as well as a high mortality rate (Kasalický et al., 2010). It was found to be positively related to air temperature. During the cooling period, the decrease in water temperature and DOC concentration might have actually reduced the adaptability and competitiveness of Limnohabitans compared to other bacteria. The relative rapid increase in their relative abundance may have been due to their rapid absorption of nutrients. Synechococcus was the only genus affiliated to Cyanobacteria. Typically, it is found to be abundant in oligotrophic environments under well-illuminated conditions in the euphotic zone (Ruber et al. 2016). The relatively low growth rates might have been exceeded by higher flow-through as observed during the cooling period. Sediminibacterium, affiliated to Bacteroidetes, has been isolated from sediment (Qu \& Yuan, 2008), soil (Kim et al., 2013), and activated sludge (Ayarza et al., 2014). Nutrient supply and temperature were most closely related to Sediminibacterium net production and growth (Sander $\&$ Kalff, 1993). Compared to the cooling period, the relative abundance of Sediminibacterium was higher under warmer weather conditions and higher DOC concentrations. It is concluded that the two meteorological factors, air temperature and precipitation, were directly and indirectly related to the observed change in the bacterial community composition.

\section{Conclusion}

In this study, the bacterial community composition changed substantially during a short-term deterioration in weather conditions as revealed at the taxonomic level of phylum, class, and genus. This significant change seemed to be caused directly and indirectly by the decreased air temperature and increased precipitation, resulting in the cooling of lake water by terrestrial runoff and increased flow-through. Notably, the planktonic bacterial community structure returned to the previous state, implying a re-installation of the original environmental conditions. We conclude that, in comparison with lowland lakes, changes in weather conditions during the summer growing season can have a more direct impact on planktonic bacterial community structure. Thus, the change in weather conditions can increase variability in the planktonic bacterial community structure and can overrule other more constant factors such as nutrient availability. Moreover, the reestablishment of the bacterial planktonic community structure to a previous state at the start of the study period implies rather robust planktonic ecological conditions.

Acknowledgements Several high school students (Anton Gimpl, Lisa Schindlegger, and Simon Urschitz) from HLFS Ursprung/Elixhausen stayed at the lakeside overnight to perform sampling. Sabine Wanzenböck assisted in the communication between high school students and teachers. We are most grateful to the local population for providing regular access to the Giglachsee Lake ("Wegegemeinschaft Ursprungalm") for sampling and to Mathias Keinprecht (Ignaz Mattis Hütte). Josef Franzoi and Roland Psenner (University of Innsbruck) performed the chemical analysis. Two anonymous reviewers and the editor commented on an earlier version of this manuscript. T.M. and Y.J. were supported by the Chinese Scholarship Council as well as the German Research Foundation (DFG Emmy Noether program; DE 2360/1-1) awarded to L.D. The sampling and data acquisition were funded by the Nationalkomitee Alpenforschung of the Austrian Academy of Sciences, Project: DETECTIVE (Decadal Detection of Biodiversity in Alpine Lakes) to R.K.

Funding Open access funding provided by University of Innsbruck and Medical University of Innsbruck.

Open Access This article is distributed under the terms of the Creative Commons Attribution 4.0 International License (http:// creativecommons.org/licenses/by/4.0/), which permits unrestricted use, distribution, and reproduction in any medium, provided you give appropriate credit to the original author(s) and the source, provide a link to the Creative Commons license, and indicate if changes were made.

\section{References}

Allgaier, M. \& H.-P. Grossart, 2006. Seasonal dynamics and phylogenetic diversity of free-living and particle- 
associated bacterial communities in four lakes in northeastern Germany. Aquatic Microbial Ecology 45: 115-128.

Allison, S. \& J. Martiny, 2008. Resistance, resilience, and redundancy in microbial communities. In Avise, J. C., S. Hubbell \& F. J. Ayala (eds), In the Light of Evolution: Volume II: Biodiversity and Extinction. National Academies Press (US), Washington, DC: 149-165.

Ayarza, J. M., E. L. Figuerola \& L. Erijman, 2014. Draft genome sequences of type strain Sediminibacterium salmoneum NJ-44 and Sediminibacterium sp. strain C3, a novel strain isolated from activated sludge. Genome Announcements 2: e01073-13.

Battarbee, R. W., J.-A. Grytnes, R. Thompson, P. G. Appleby, J. Catalan, A. Korhola, H. Birks, E. Heegaard \& A. Lami, 2002. Comparing palaeolimnological and instrumental evidence of climate change for remote mountain lakes over the last 200 years. Journal of Paleolimnology 28: 161-179.

Bel'kova, N., L. Denisova, E. Manakova, E. Zaǐchikov \& M. Grachev, 1996. Species diversity of deep water microorganisms in Lake Baikal, detected by $16 \mathrm{~S}$ rRNA sequences. Doklady Akademii nauk 348: 692.

Bertilsson, S., A. Eiler, A. Nordqvist \& N. O. G. Jørgensen, 2007. Links between bacterial production, amino-acid utilization and community composition in productive lakes. The ISME Journal 1: 532.

Caporaso, J. G., K. Bittinger, F. D. Bushman, T. Z. DeSantis, G. L. Andersen \& R. Knight, 2009. PyNAST: a flexible tool for aligning sequences to a template alignment. Bioinformatics 26: 266-267.

Caporaso, J. G., J. Kuczynski, J. Stombaugh, K. Bittinger, F. D. Bushman, E. K. Costello, N. Fierer, A. G. Pena, J. K. Goodrich \& J. I. Gordon, 2010. QIIME allows analysis of high-throughput community sequencing data. Nature Methods 7: 335.

Castro, H. F., A. T. Classen, E. E. Austin, R. J. Norby \& C. W. Schadt, 2010. Soil microbial community responses to multiple experimental climate change drivers. Applied and Environmental Microbiology 76: 999-1007.

Chanika, E., D. Georgiadou, E. Soueref, P. Karas, E. Karanasios, N. G. Tsiropoulos, E. A. Tzortzakakis \& D. G. Karpouzas, 2011. Isolation of soil bacteria able to hydrolyze both organophosphate and carbamate pesticides. Bioresource technology 102(3): 3184-3192.

Comte, J., S. Jacquet, S. Viboud, D. Fontvieille, A. Millery, G. Paolini \& I. Domaizon, 2006. Microbial community structure and dynamics in the largest natural French lake (Lake Bourget). Microbial Ecology 52: 72-89.

Corno, G., 2006. Effects of nutrient availability and Ochromonas sp. predation on size and composition of a simplified aquatic bacterial community. FEMS Microbiology Ecology 58: 354-363.

Corno, G., B. E. Modenutti, C. Callieri, E. G. Balseiro, R. Bertoni \& E. Caravatia, 2009. Bacterial diversity and morphology in deep ultraoligotrophic Andean lakes: the role of UVR on vertical distribution. Limnology and Oceanography 54: 1098-1112.

Crump, B. C., G. W. Kling, M. Bahr \& J. E. Hobbie, 2003. Bacterioplankton community shifts in an arctic lake correlate with seasonal changes in organic matter source. Applied and Environmental Microbiology 69: 2253-2268.
DeSantis, T. Z., P. Hugenholtz, N. Larsen, M. Rojas, E. L. Brodie, K. Keller, T. Huber, D. Dalevi, P. Hu \& G. L. Andersen, 2006. Greengenes, a chimera-checked $16 \mathrm{~S}$ rRNA gene database and workbench compatible with ARB. Applied and Environmental Microbiology 72: 5069-5072.

Downing, A. L., K. M. DeVanna, C. N. Rubeck-Schurtz, L. Tuhela \& H. Grunkemeyer, 2008. Community and ecosystem responses to a pulsed pesticide disturbance in freshwater ecosystems. Ecotoxicology 17(6): 539-548.

Edgar, R. C., 2010. Search and clustering orders of magnitude faster than BLAST. Bioinformatics 26: 2460-2461.

Eiler, A. \& S. Bertilsson, 2004. Composition of freshwater bacterial communities associated with cyanobacterial blooms in four Swedish lakes. Environmental Microbiology 6: 1228-1243.

Haukka, K., E. Kolmonen, R. Hyder, J. Hietala, K. Vakkilainen, T. Kairesalo, H. Haario \& K. Sivonen, 2006. Effect of nutrient loading on bacterioplankton community composition in lake mesocosms. Microbial Ecology 51: 137-146.

Heiri, O. \& A. F. Lotter, 2003. 9000 years of chironomid assemblage dynamics in an Alpine lake: long-term trends, sensitivity to disturbance, and resilience of the fauna. Journal of Paleolimnology 30(3): 273-289.

Hibbing, M. E., C. Fuqua, M. R. Parsek \& S. B. Peterson, 2010. Bacterial competition: surviving and thriving in the microbial jungle. Nature Reviews Microbiology 8: 15.

Hongve, D., G. Riise \& J. F. Kristiansen, 2004. Increased colour and organic acid concentrations in Norwegian forest lakes and drinking water-a result of increased precipitation? Aquatic Sciences 66: 231-238.

Hornák, K., J. Jezbera, J. Nedoma, J. M. Gasol \& K. Simek, 2006. Effects of resource availability and bacterivory on leucine incorporation in different groups of freshwater bacterioplankton, assessed using microautoradiography. Aquatic Microbial Ecology 45: 277-289.

Huang, X., W. Li, D. Zhang \& W. Qin, 2013. Ammonium removal by a novel oligotrophic Acinetobacter sp. Y16 capable of heterotrophic nitrification-aerobic denitrification at low temperature. Bioresource Technology 146: 44-50.

Humbert, J. F., U. Dorigo, P. Cecchi, B. Le Berre, D. Debroas \& M. Bouvy, 2009. Comparison of the structure and composition of bacterial communities from temperate and tropical freshwater ecosystems. Environmental Microbiology 11: 2339-2350.

Huse, S. M., L. Dethlefsen, J. A. Huber, D. M. Welch, D. A. Relman \& M. L. Sogin, 2008. Exploring microbial diversity and taxonomy using SSU rRNA hypervariable tag sequencing. PLoS Genetics 4: e1000255.

Jiang, Y., H. Huang, T. Ma, J. Ru, S. Blank, R. Kurmayer \& L. Deng, 2019. Temperature response of planktonic microbiota in remote alpine lakes. Frontiers in microbiology 10 : 1714.

Jones, S. E., C.-Y. Chiu, T. K. Kratz, J.-T. Wu, A. Shade \& K. D. McMahon, 2008. Typhoons initiate predictable change in aquatic bacterial communities. Limnology and Oceanography 53(4): 1319-1326.

Jossi, M., 2008. Rhizosphere bacterial communities associated with Lolium perenne. Université de Neuchâtel. 
Kasalický, V., J. Jezbera, K. Šimek \& M. W. Hahn, 2010. Limnohabitans planktonicus sp. nov. and Limnohabitans parvus sp. nov., planktonic betaproteobacteria isolated from a freshwater reservoir, and emended description of the genus Limnohabitans. International Journal of Systematic and Evolutionary Microbiology 60: 2710-2714.

Kasana, R. C., 2017. Bacterial Diversity in Cold Environments of Indian Himalayas Mining of Microbial Wealth and MetaGenomics. Springer, Berlin: 83-99.

Kim, Y.-J., N.-L. Nguyen, H.-Y. Weon \& D.-C. Yang, 2013. Sediminibacterium ginsengisoli $\mathrm{sp}$. nov., isolated from soil of a ginseng field, and emended descriptions of the genus Sediminibacterium and of Sediminibacterium salmoneum. International Journal of Systematic and Evolutionary Microbiology 63: 905-912.

Kolmonen, E., K. Sivonen, J. Rapala \& K. Haukka, 2004. Diversity of cyanobacteria and heterotrophic bacteria in cyanobacterial blooms in Lake Joutikas, Finland. Aquatic Microbial Ecology 36: 201-211.

Kröel-Dulay, G., J. Ransijn, I. K. Schmidt, C. Beier, P. De Angelis, G. De Dato, J. S. Dukes, B. Emmett, M. Estiarte \& J. Garadnai, 2015. Increased sensitivity to climate change in disturbed ecosystems. Nature Communications 6: 6682.

Lepš, J. \& P. Šmilauer, 2003. Multivariate Analysis of Ecological Data Using CANOCO. Cambridge University Press, Cambridge.

Lindström, E. \& E. Leskinen, 2002. Do neighboring lakes share common taxa of bacterioplankton? Comparison of $16 \mathrm{~S}$ rDNA fingerprints and sequences from three geographic regions. Microbial Ecology 44: 1-9.

Lindström, E. S., M. P. Kamst-Van Agterveld \& G. Zwart, 2005. Distribution of typical freshwater bacterial groups is associated with $\mathrm{pH}$, temperature, and lake water retention time. Applied and Environmental Microbiology 71(12): 8201-8206.

Magnea, U., R. Sciascia, F. Paparella, R. Tiberti \& A. Provenzale, 2013. A model for high-altitude alpine lake ecosystems and the effect of introduced fish. Ecological Modelling 251: 211-220.

Marasco, R., E. Rolli, M. Fusi, A. Cherif, A. Abou-Hadid, U. ElBahairy, S. Borin, C. Sorlini \& D. Daffonchio, 2013. Plant growth promotion potential is equally represented in diverse grapevine root-associated bacterial communities from different biopedoclimatic environments. BioMed research international. https://doi.org/10.1155/2013/ 491091.

Nelson, C. E., 2009. Phenology of high-elevation pelagic bacteria: the roles of meteorologic variability, catchment inputs and thermal stratification in structuring communities. The ISME Journal 3: 13.

Newton, R. J., S. E. Jones, A. Eiler, K. D. McMahon \& S. Bertilsson, 2011. A guide to the natural history of freshwater lake bacteria. Microbiology and Molecular Biology Reviews 75: 14-49.

O’Brien, W. J., M. Bahr, A. E. Hershey, J. E. Hobbie, G. W. Kipphut, G. W. Kling, H. Kling, M. McDonald, M. C. Miller \& P. Rublee, 1997. The Limnology of Toolik Lake Freshwaters of Alaska. Springer, Berlin: 61-106.

Paerl, H. W. \& J. Huisman, 2008. Blooms like it hot. Science 320: $57-58$.
Posch, T., B. Mindl, K. Horňák, J. Jezbera, M. M. Salcher, B. Sattler, B. Sonntag, J. Vrba \& K. Šimek, 2007. Biomass reallocation within freshwater bacterioplankton induced by manipulating phosphorus availability and grazing. Aquatic Microbial Ecology 49: 223-232.

Power, M. L., J. Littlefield-Wyer, D. M. Gordon, D. A. Veal \& M. B. Slade, 2005. Phenotypic and genotypic characterization of encapsulated Escherichia coli isolated from blooms in two Australian lakes. Environmental Microbiology 7: 631-640.

Qu, J.-H. \& H.-L. Yuan, 2008. Sediminibacterium salmoneum gen. nov., sp. nov., a member of the phylum Bacteroidetes isolated from sediment of a eutrophic reservoir. International Journal of Systematic and Evolutionary Microbiology 58: 2191-2194.

Rasconi, S., K. Winter \& M. J. Kainz, 2017. Temperature increase and fluctuation induce phytoplankton biodiversity loss-Evidence from a multi-seasonal mesocosm experiment. Ecology and Evolution 7: 2936-2946.

Ren, L., D. He, J. Zeng \& Q. L. Wu, 2013. Bacterioplankton communities turn unstable and become small under increased temperature and nutrient-enriched conditions. FEMS Microbiology Ecology 84: 614-624.

Rofner, C., H. Peter, N. Catalán, F. Drewes, R. Sommaruga \& M. T. Pérez, 2017. Climate-related changes of soil characteristics affect bacterial community composition and function of high altitude and latitude lakes. Global Change Biology 23: 2331-2344.

Ruber, J., F. R. Bauer, A. D. Millard, U. Raeder, J. Geist \& K. Zwirglmaier, 2016. Synechococcus diversity along a trophic gradient in the Osterseen Lake District, Bavaria. Microbiology 162(12): 2053-2063.

Salcher, M. M., J. Pernthaler \& T. Posch, 2010. Spatiotemporal distribution and activity patterns of bacteria from three phylogenetic groups in an oligomesotrophic lake. Limnology and Oceanography 55: 846-856.

Sander, B. C. \& J. Kalff, 1993. Factors controlling bacterial production in marine and freshwater sediments. Microbial Ecology 26: 79-99.

Scheffer, M. \& S. R. Carpenter, 2003. Catastrophic regime shifts in ecosystems: linking theory to observation. Trends in Ecology \& Evolution 18(12): 648-656.

Seekell, D. A., S. R. Carpenter \& M. L. Pace, 2011. Conditional heteroscedasticity as a leading indicator of ecological regime shifts. The American Naturalist 178(4): 442-451.

Shade, A., J. S. Read, D. G. Welkie, T. K. Kratz, C. H. Wu \& K. D. McMahon, 2011. Resistance, resilience and recovery: aquatic bacterial dynamics after water column disturbance. Environmental Microbiology 13(10): 2752-2767.

Shade, A., H. Peter, S. Allison, D. Baho, M. Berga, H. Buergmann, D. Huber, S. Langenheder, J. Lennon, J. Martiny, K. Matulich, T. Schmidt \& J. Handelsman, 2012. Fundamentals of microbial community resistance and resilience. Frontiers in Microbiology 3: 417.

Stepanauskas, R., M. A. Moran, B. A. Bergamaschi \& J. T. Hollibaugh, 2003. Covariance of bacterioplankton composition and environmental variables in a temperate delta system. Aquatic Microbial Ecology 31: 85-98.

Taipale, S., R. I. Jones \& M. Tiirola, 2009. Vertical diversity of bacteria in an oxygen-stratified humic lake, evaluated using 
DNA and phospholipid analyses. Aquatic Microbial Ecology 55: 1-16.

Thompson, R., C. Kamenik \& R. Schmidt, 2005. Ultra-sensitive Alpine lakes and climate change. Journal of Limnology 64(2): 139-152.

Tranvik, L. \& M. Jansson, 2002. Climate change (Communication arising): terrestrial export of organic carbon. Nature 415: 861.

Van Der Gucht, K., K. Sabbe, L. De Meester, N. Vloemans, G. Zwart, M. Gillis \& W. Vyverman, 2001. Contrasting bacterioplankton community composition and seasonal dynamics in two neighbouring hypertrophic freshwater lakes. Environmental Microbiology 3: 680-690.

Weckström, K., J. Weckström, K. Huber, C. Kamenik, R. Schmidt, W. Salvenmoser, M. Rieradevall, T. Weisse, R. Psenner \& R. Kurmayer, 2016. Impacts of climate warming on Alpine lake biota over the past decade. Arctic, Antarctic, and Alpine Research 48: 361-376.

Whalen, S. \& J. Cornwell, 1985. Nitrogen, phosphorus, and organic carbon cycling in an arctic lake. Canadian Journal of Fisheries and Aquatic Sciences 42: 797-808.
Worrall, F., N. J. Howden, T. P. Burt \& R. Bartlett, 2018. Declines in the dissolved organic carbon (DOC) concentration and flux from the UK. Journal of Hydrology 556: 775-789.

Yadav, A. N., S. G. Sachan, P. Verma, R. Kaushik \& A. K. Saxena, 2016. Cold active hydrolytic enzymes production by psychrotrophic Bacilli isolated from three subglacial lakes of NW Indian Himalayas. Journal of Basic Microbiology 56(3): 294-307.

Yannarell, A. C. \& E. W. Triplett, 2004. Within-and betweenlake variability in the composition of bacterioplankton communities: investigations using multiple spatial scales. Applied and Environmental Microbiology 70: 214-223.

Yao, S., J. Ni, T. Ma \& C. Li, 2013. Heterotrophic nitrification and aerobic denitrification at low temperature by a newly isolated bacterium, Acinetobacter sp. HA2. Bioresource Technology 139: 80-86.

Publisher's Note Springer Nature remains neutral with regard to jurisdictional claims in published maps and institutional affiliations. 